\title{
The Levels of Ghrelin, Leptin, TNF- $\alpha$, and IL-6 in Liver Cirrhosis and Hepatocellular Carcinoma due to HBV and HDV Infection
}

\author{
Huseyin Ataseven, ${ }^{1}$ Ibrahim Halil Bahcecioglu, ${ }^{1}$ Nalan Kuzu, ${ }^{2}$ Mehmet Yalniz, ${ }^{1}$ \\ Selman Celebi, ${ }^{1}$ Ahmet Erensoy, ${ }^{3}$ and Bilal Ustundag ${ }^{4}$

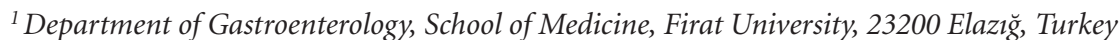 \\ ${ }^{2}$ Department of Internal Medicine, School of Medicine, Firat University, 23200 Elaziğ, Turkey \\ ${ }^{3}$ Department of Microbiology, School of Medicine, Firat University, 23200 Elazı̆̆, Turkey \\ ${ }^{4}$ Department of Biochemistry, School of Medicine, Firat University, 23200 Elaziğ, Turkey
}

Received 11 March 2006; Revised 29 March 2006; Accepted 30 March 2006

\begin{abstract}
Background/Aim. Malnutrition, a common problem in liver cirrhosis and HCC, may readily deteriorate the clinical functions with resultant poor prognosis. Beside the hyper catabolic state frequently encountered in chronic liver disease and HCC, anorexia and reduced food intake also worsen the malnutrition. The recently discovered peptide hormone ghrelin acts as a counterpart of leptin in regulation of food intake and fat utilization. The aim of the present study was to investigate the ghrelin and leptin levels in cirrhosis and HCC due to hepatitis B and D viruses, and the association of ghrelin and leptin with TNF- $\alpha$, IL-6 and the severity of the disease. Materials and methods. We measured serum ghrelin, leptin, TNF- $\alpha$, and IL-6 levels using specific immunoassay in 45 patients ( 23 cirrhosis, $22 \mathrm{HCC}$ ) with HBV and/or HDV and in 25 control subjects. Results. In comparison to controls, serum ghrelin, TNF- $\alpha$, and IL-6 levels were significantly higher in cirrhosis and HCC $(P<.05)$, whereas serum leptin levels were found decreased $(P<.05)$. There was a positive correlation between ghrelin and TNF- $\alpha$, and a negative correlation between leptin and TNF- $\alpha(P<.05)$. Conclusion. In cirrhosis and HCC due to HBV or HDV, serum ghrelin levels were increased with a corresponding decrease in serum leptin concentrations, acting as a physiological counterpart of ghrelin. The increasing of ghrelin is more prominent in Child C cirrhosis and the level was correlated with TNF- $\alpha$. The presence of nutritional and metabolic abnormalities, including malnutrition, in cirrhosis and HCC may, at least partly, elucidate high ghrelin and low leptin levels.
\end{abstract}

Copyright (C) 2006 Huseyin Ataseven et al. This is an open access article distributed under the Creative Commons Attribution License, which permits unrestricted use, distribution, and reproduction in any medium, provided the original work is properly cited.

\section{INTRODUCTION}

Viral hepatitis is the leading cause of liver cirrhosis and hepatocellular carcinoma (HCC) [1]. HCC is the fifth most common cancer and the third leading cause of cancer-related mortality worldwide [2]. Malnutrition is a common problem in liver cirrhosis and HCC. This may cause deterioration of clinical functions with resultant poor prognosis [3-7]. Liver failure causes both decreased protein synthesis and enhanced protein breakdown, which together with anorexia and reduced food intake can lead to severe protein energy malnutrition and limit the capacity for regeneration and functional recovery of the liver [8].

Ghrelin is a novel endogenous ligand for the growth hormone $(\mathrm{GH})$ secretagogue receptor that has recently been isolated from both human and rat stomach [9]. Ghrelin controls energy balance, enhancing fat mass deposition and food intake through the activation of the hypothalamic nuclei and the promotion of neuropeptide Y (NPY) and agouti-related protein (AGRP) expression [10, 11]. Ghrelin administration stimulates GH secretion independent of hypothalamic GHreleasing hormone, and also causes weight gain and adiposity by increasing food intake and reducing fat utilization in rodents $[12,13]$. Leptin is a peptide hormone and is predominantly produced by adipocytes [14]. Leptin is postulated to regulate energy balance by suppressing appetite and increasing energy expenditure [15-17]. The mechanism of action in the hypothalamic nuclei is antagonistic to ghrelin: leptin inhibits NPY and AGRP [18]. Also leptin plays a role in the modulation of immune response and inflammation. The increase in leptin production that occurs during infection and inflammation strongly suggests that leptin is a part 
of cytokine cascade $[19,20]$. Recent attention has been focused on the liver profibrogenic role of leptin in animal models [21].

The effect of ghrelin-like leptin is not exclusively mediated by direct hypothalamic receptor activation, but also by modulating cytokines [22]. Tumor necroses factor $\alpha$ (TNF$\alpha$ ) and interleukin-6 (IL-6) are pleiotropic cytokines with numerous immunologic and metabolic actions $[23,24]$. The TNF- $\alpha$ system activity is increased in liver cirrhosis and generally thought to be associated with several known cirrhosisrelated complications such as hyperdynamic circulation, susceptibility to infection, and hepatic encephalopathy $[25,26]$.

IL-6 is generally considered to be an important cytokine in the network of cytokines that regulate immune reactions and acute phase responses [27]. A link between IL-6 and liver fibrosis/cirrhosis has also been reported [28]. Activation of cytokine system, as observed in several chronic inflammatory conditions including liver cirrhosis, may result in increased energy expenditure and reduced nutrition intake [29].

Patients with chronic liver diseases usually exhibit a lean body as a result of hypermetabolism. They also suffer from a diminished food intake and malnutrition status and leptin is thought to be involved [30]. However there have been very few reports on the association of ghrelin, leptin, and cytokines in liver cirrhosis and HCC. Therefore in the present study we evaluated the ghrelin and leptin levels in cirrhosis and HCC due to hepatitis B and D viruses, and the association of ghrelin and leptin with TNF- $\alpha$, IL-6.

\section{MATERIALS AND METHODS}

\section{Patients}

Forty five patients (23 cirrhosis, $22 \mathrm{HCC}$ ) with HBs Ag (+) and/or antidelta $(+)$ were enrolled to the study. The diagnosis of cirrhosis was based on the typical findings of hepatic cirrhotic appearance, splenomegaly, esophageal varices, and ascites (by ultrasonography and upper gastrointestinal endoscope examinations, with supporting biochemical data or histologically [31]). The diagnosis of HCC was made according to Barcelona classification [32]. Exclusion criteria were included: (i) concomitant acute complications, such as gastrointestinal hemorrhage, hepatic, encephalopathy or clinical signs of infection, (ii) renal insufficiency, (iii) the patient was treated with drugs that alter carbohydrate metabolism, or hypothalamic-pituitary axis.

Twenty five healthy individuals with normal medical history, physical examination, and blood chemistry served as control group. The local ethics committee approved the study protocol. Written informed consent was obtained prior to enrolment.

\section{Laboratory investigation and immunoassays}

All blood samples were drawn at $08: 00-09: 00$ am after an overnight fast. The aspartate aminotransferase, alanine aminotransferase, serum albumin, total bilirubin, and alphafetoprotein were measured at biochemistry department in
TABle 1: Demographic and clinical characteristics of control and patients groups.

\begin{tabular}{lccc}
\hline & $\begin{array}{c}\text { Control } \\
(n=25)\end{array}$ & $\begin{array}{c}\text { Cirrhosis } \\
(n=23)\end{array}$ & $\begin{array}{c}\text { HCC } \\
(n=22)\end{array}$ \\
\hline Age (year) & $37,12 \pm 7,57$ & $45,54 \pm 7,99$ & $59,82 \pm 8,77$ \\
Sex (F/M) & $14 / 11$ & $12 / 11$ & $7 / 15$ \\
\hline Etiology & & 13 & 13 \\
Hepatitis B & 10 & 9 \\
Hepatitis B+D & 5 & 3 \\
\hline Child-Pugh & 5 & 8 \\
Child A & 10 & 11 \\
Child B & $14 / 23$ & $17 / 22$ \\
Child C & & & \\
\hline Ascites & & - & $37,29 \pm 25,63$ \\
\hline Tumor & & & \\
Single/multiple & & & \\
\hline Tumor Size $(\mathrm{mm})$ & & & \\
\hline
\end{tabular}

routine clinical practice. Serum samples for ghrelin, leptin, TNF- $\alpha$, and IL- 6 were stored at $-20^{\circ} \mathrm{C}$. Ghrelin, leptin, TNF$\alpha$, and IL-6 levels were analyzed with ELISA kits (TNF- $\alpha$, IL6 kit was purchased from Bio-Source International Inc, 542, Flynn Road, Camarillo, California, USA; Ghrelin kit from Phoenix International, Inc, USA; and Leptin kit from DRG International, Inc, USA).

\section{Statistical analyses}

All data were analyzed by SPSS software (Statistical Package for the Social Sciences), version 10.0 for Windows. Data were presented as mean \pm standard deviation unless noted as different. Comparisons between subjects groups were analyzed using the nonparametric Mann-Whitney $U$ test. The relationship between ghrelin, leptin, TNF- $\alpha$, IL-6, AFP, and Child-Pugh score were determined by Spearman's correlation. $P$ value of $<.05$ was considered statistically significant.

\section{RESULTS}

Demographic and clinical characteristics of control and patient groups are shown in Table 1. Mean age and gender between the control group and cirrhosis group were comparable $(P>.05)$. Patients in the HCC group were older, and more likely to be male than the cirrhotic patients and control group $(P<.05)$. All the patients in cirrhosis and HCC group were positive for hepatitis $\mathrm{B}$ surface antigen. Antidelta anticore was present in $43.5 \%$ of the cirrhotic group and $40.9 \%$ of the HCC group. Presence of HDV between cirrhosis and HCC groups was comparable $(P>.05)$.

According to Child-Pugh stage, five $(21.7 \%)$ of the 23 cirrhotic patients were Child A, eight $(34.8 \%)$ were Child B, ten (43.5\%) were Child C; three (13.6\%) of the HCC patients were Child A, eight (36.4\%) were Child B, eleven (50\%) were Child C. 
TABLE 2: Biochemical characteristics of control and patients groups.

\begin{tabular}{lccc}
\hline & $\begin{array}{c}\text { Control } \\
(n=25)\end{array}$ & $\begin{array}{c}\text { Cirrhosis } \\
(n=23)\end{array}$ & $\begin{array}{c}\text { HCC } \\
(n=22)\end{array}$ \\
\hline Ghrelin $(\mathrm{ng} / \mathrm{mL})$ & $7.55 \pm 0.98$ & $9.71 \pm 1.67^{*}$ & $8.13 \pm 0.77^{\dagger}$ \\
Leptin $(\mathrm{ng} / \mathrm{mL})$ & $10.25 \pm 2.49$ & $4.23 \pm 2.06^{*}$ & $4.18 \pm 1.68^{\dagger}$ \\
TNF- $\alpha(\mathrm{pg} / \mathrm{mL})$ & $3.33 \pm 1.21$ & $10.38 \pm 3.88^{*}$ & $8.8 \pm 3.4^{\dagger}$ \\
IL-6 $(\mathrm{pg} / \mathrm{mL})$ & $4.56 \pm 2.0$ & $15.65 \pm 5.19^{*}$ & $33.27 \pm 16.38^{\dagger \dagger}$ \\
AST $(\mathrm{U} / \mathrm{L})$ & $20,62 \pm 6,09$ & $103,16 \pm 47,13^{* *}$ & $158,71 \pm 65,61^{\dagger \dagger \dagger}$ \\
ALT $(\mathrm{U} / \mathrm{L})$ & $19,25 \pm 4,58$ & $81,16 \pm 47,62^{* *}$ & $117,33 \pm 75,09^{\dagger \dagger \dagger}$ \\
Bilirubin $(\mathrm{mg} / \mathrm{dL})$ & $1,07 \pm 0,17$ & $3,94 \pm 3,41^{*}$ & $3,01 \pm 2,61^{\dagger}$ \\
TProtein $(\mathrm{gr} / \mathrm{dL})$ & $7,14 \pm 0,62$ & $6,81 \pm 1,01$ & $7,11 \pm 0,91$ \\
Albumine $(\mathrm{gr} / \mathrm{dL})$ & $4,41 \pm 0,35$ & $2,75 \pm 0,76^{* *}$ & $2,89 \pm 0,72^{\dagger \dagger \dagger}$ \\
AFP $(\mathrm{IU} / \mathrm{mL})$ & - & - & $3346 \pm 4953$ \\
\hline
\end{tabular}

$* P<.05$ control: cirrhosis group

${ }^{* *} P<.001$ control: cirrhosis group

${ }^{\dagger} P<.05$ control: HCC group

${ }^{\dagger} P<.01$ control: HCC group

${ }^{+\dagger \dagger} P<.01$ control: HCC group.

Serum ghrelin, TNF- $\alpha$, and IL-6 levels were significantly higher in cirrhosis and HCC groups compared to in the control group $(P<.05)$. On the other hand, serum leptin levels were significantly lower in cirrhosis and HCC groups compared to in the control group $(P<.05)$. These differences were not gender specific in the cirrhosis and HCC groups $(P>.05)$. Serum ghrelin levels in Child $\mathrm{C}$ cirrhosis tended to be higher than Child A cirrhosis $(P<.05)$. Serum levels of ghrelin, leptin, TNF- $\alpha$, IL-6, liver function tests, and alpha feto protein (AFP) are shown in Table 2.

A significant positive correlation was found between ghrelin and TNF- $\alpha,(r: 0.290, P<.05)$. There was a negative correlation between ghrelin and leptin $(r=0.302, P<.05)$. However no correlation was found between ghrelin, leptin and AST, ALT, AFP $(P>.05)$. Correlations of ghrelin with leptin and TNF- $\alpha$ are shown in Figures 1 and 2.

\section{DISCUSSION}

HBV infection is still the most serious cause of chronic liver disease in Turkey [33]. Turkey is one of the countries with intermediate endemicity in the European region of the World Health Organization (WHO) [34]. A higher frequency of dual HBV/HDV infection has been described in patients of HCC and consequential severe necro-inflammation may be an additional factor for the promotion of HCC [35].

The nutritional and metabolic consequences of cirrhosis have attracted considerable interest over the past decade because malnutrition and hypermetabolism are commonly found in cirrhotic patients [3]. In addition, malnutrition is a well-established risk factor influencing survival in patients with cirrhosis and can modify the prognosis [36].

Ghrelin and leptin are important regulators of appetite and energy balance [22]. There are numerous studies about the role of leptin in malnutrition of cirrhotic patients. But little is known about malnutrition in HBV and HDV coinfected cirrhosis and HCC. This is the first study concerning this issue.

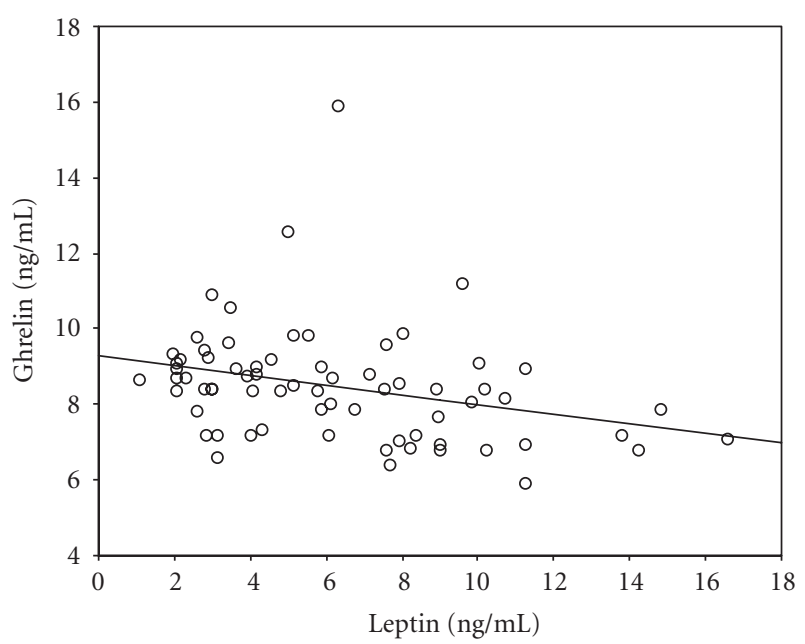

FIGURE 1: The relation of ghrelin and leptin. There was a negative correlation between ghrelin and leptin $(r: 0.302, P<.05)$.

In accordance with the previous report [37], we established that serum ghrelin levels increased in cirrhosis and HCC due to HBV or HDV than control group, whereas leptin was found decreased in cirrhosis and HCC.

The recently discovered hormone, ghrelin, may well be the bridge connecting with general metabolism. As ghrelin anticipates the initiation of meals and releases $\mathrm{GH}$, it has been postulated that ghrelin integrates anabolic changes in the body. In catabolic situations like in cirrhosis, raised ghrelin levels may induce a combination of enhanced food intake, increased gastric emptying and food assimilation. These actions of ghrelin are the opposite of leptin which reduces food intake and selectively eliminates fat mass. Thus, both peptides may act as physiological regulators of energy balance in an extensive range [38]. 


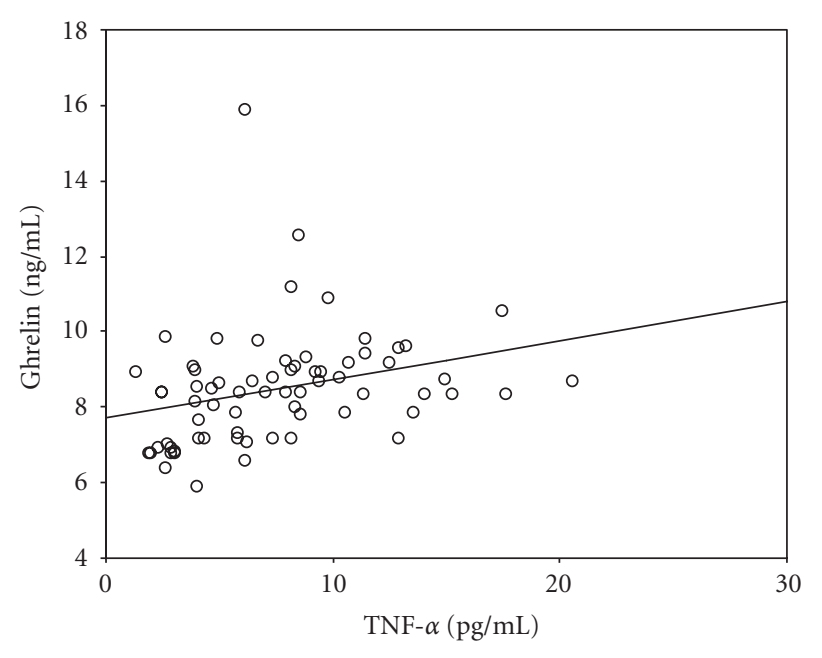

FIGURE 2: The relation of ghrelin and TNF- $\alpha$. There was a positive correlation between ghrelin and TNF- $\alpha(r: 0.290, P<.05)$.

Several studies have shown that circulating leptin levels are modestly elevated in patients with alcoholic cirrhosis $[39,40]$. While some studies have supported these findings, others have reported low serum leptin levels in posthepatitis cirrhotic patients [30, 41-45]. In addition, nutritional status of cirrhotic cases represents a wide range, from normal to severe malnutrition, connected with the severity of the disease $[7,41]$. It is well known that insulin resistance is present in cirrhosis due to HCV or alcohol $[46,47]$. Insulin resistance, therefore, might well explain elevated leptin levels in these patients. Leptin is predominantly produced by adipocytes. Greco A V et al [44] demonstrated that the decrease in circulating levels of leptin strongly reflects the degree of malnutrition and fat mass in posthepatitis cirrhosis. Insulin resistance is less common in cirrhosis due to HBV or HDV than alcohol or HCV. Hypoleptinemia, thus, could well be a consequence of malnutrition and fat mass reduction in HBV or HDV cirrhosis rather than the insulin resistance.

Serum ghrelin levels were significantly elevated in Child $\mathrm{C}$ cirrhosis compared to Child A grade $(P<.05)$. Since the likelihood of metabolic decompensation and clinical complications increases with Child's classification [48], ghrelin could potentially counteract these challenges in Child C cirrhosis by its various metabolic functions like the modulation of energy balance, stimulation of appetite, and food intake.

In keeping with a recent study [37], we found serum ghrelin levels significantly elevated in HCC due to HBV or HDV than in the control group. Meanwhile serum leptin levels in HCC were significantly lower than in the control group. Serum ghrelin and leptin concentrations, however, did not differ between cirrhosis and HCC. Since HCC patients predominantly composed with cirrhotic patients in the present study, the change in ghrelin and leptin may be relevant to the metabolic disturbances due to cirrhosis rather than HCC. Tacke et al reported a correlation with AFP and serum ghrelin levels. Nevertheless, our results did not corroborate this finding.
We found that serum TNF- $\alpha$ significantly increased in cirrhosis and HCC $(P<.05$, for both). Similarly, serum IL-6 was increased in both groups but the change was more distinctive in HCC group $(P<.001)$. Increased endogenous TNF- $\alpha$ in advanced liver disease is generally believed to be a consequence of chronic liver failure, which is associated with endotoxin-dependent macrophage stimulation and with a decrease in cytokine clearance [49]. Similarly, a link between IL-6 and liver fibrosis/cirrhosis has also been reported [28]. TNF- $\alpha$ and IL- 6 appear to be important cachectic process mediators; although this association is not completely established $[50,51]$. Also Toda et al [52] reported that IL-6 has a direct mitogenic effect on hepatic stellate cells. The presence of more prominent raise of IL-6 in HCC may be linked to mitogenic affect of IL-6.

In the present study, TNF- $\alpha$ correlated positively with ghrelin and negatively with leptin. The relation of ghrelin with TNF- $\alpha$ raises the possibility of the direct effect of TNF$\alpha$ upon ghrelin or the impact of disease severity upon both ghrelin and TNF- $\alpha$. The effect of leptin is not exclusively mediated by direct hypothalamic receptor activation but also by modulating cytokines such as TNF- $\alpha[19,20]$. In the present study, contrary to previous reports, the presence of negative correlation between TNF- $\alpha$ and leptin suggests that the effect of disease severity upon leptin is a more imperative factor than TNF- $\alpha$ in cirrhosis and HCC due to HBV or HDV.

In conclusion, ghrelin level is elevated whilst leptin is decreased in cirrhosis and HCC due to HBV and HDV. Increased ghrelin levels as counterpart of decreased leptin, at least, represents malnutrition in these patients. Additionally, the relation of ghrelin with cytokines and Child-Pugh stage may be explained by the possible affect of disease severity upon ghrelin.

\section{REFERENCES}

[1] Montalto G, Cervello M, Giannitrapani L, Dantona F, Terranova A, Castagnetta LA. Epidemiology, risk factors, and natural history of hepatocellular carcinoma. Annals of the New York Academy of Sciences. 2002;963:13-20.

[2] Parkin DM, Bray F, Ferlay J, Pisani P. Estimating the world cancer burden: Globocan 2000. International Journal of Cancer. 2001;94(2):153-156.

[3] Guglielmi FW, Panella C, Buda A, et al. Nutritional state and energy balance in cirrhotic patients with or without hypermetabolism. Multicentre prospective study by the "Nutritional Problems in Gastroenterology" Section of the Italian Society of Gastroenterology (SIGE). Digestive and Liver Disease. 2005;37(9):681-688.

[4] Schütz T, Roske A-E, Lehmann A-C, Lochs H, Plauth M. Pathogenesis of malnutrition in patients with hepatocellular carcinoma (HCC). Clinical Nutrition. 1998;17(suppl 1):12-13.

[5] Merli M, Riggio O, Dally L. Does malnutrition affect survival in cirrhosis? (Policentrica Italiana Nutrizione Cirrosi). Hepatology. 1996;23(5):1041-1046.

[6] Riggio O, Angeloni S, Ciuffa L, et al. Malnutrition is not related to alterations in energy balance in patients with stable liver cirrhosis. Clinical Nutrition. 2003;22(6):553-559. 
[7] Italian Multicentre Cooperative Project on Nutrition in Liver Cirrhosis. Nutritional status in cirrhosis. Journal of Hepatology. 1994;21(3):317-325.

[8] Rock CL, Coulstan AM, Ruffin MT. Diet therapy. In: Fauci AS, Braunwald E, Isselbacher KJ, eds. Harrison's Principles of Internal Medicine. 14th ed. New York, NY: McGraw-Hil; 1998:465472.

[9] Kojima M, Hosoda H, Date Y, Nakazato M, Matsuo H, Kangawa $\mathrm{K}$. Ghrelin is a growth- hormone-releasing acylated peptide from stomach. Nature. 1999;402(6762):656-660.

[10] Nakazato M, Murakami N, Date Y, et al. A role for ghrelin in the central regulation of feeding. Nature. 2001;409(6817):194198.

[11] Shintani M, Ogawa Y, Ebihara K, et al. Ghrelin, an endogenous growth hormone secretagogue, is a novel orexigenic peptide that antagonizes leptin action through the activation of hypothalamic neuropeptide Y/Y1 receptor pathway. Diabetes. 2001;50(2):227-232.

[12] Tschop M, Smiley DL, Heiman ML. Ghrelin induces adiposity in rodents. Nature. 2000;407(6806):908-913.

[13] Wren AM, Small CJ, Ward HL, et al. The novel hypothalamic peptide ghrelin stimulates food intake and growth hormone secretion. Endocrinology. 2000;141(11):4325-4328.

[14] Friedman JM, Halas JL. Leptin and the regulation of body weight in mammals. Nature. 1998;395(6704):763-770.

[15] Caro JF, Sinha MK, Kolaczynski JW, Zhang PL, Considine RV. Leptin: the tale of an obesity gene. Diabetes. 1996;45(11): 1455-1462.

[16] Friedman JM. Leptin, leptin receptors and the control of body weight. European Journal of Medical Research. 1997;2(1):7-13.

[17] Kennedy A, Gettys TW, Watson P, et al. The metabolic significance of leptin in humans: gender-based differences in relationship to adiposity, insulin sensitivity, and energy expenditure. Journal of Clinical Endocrinology and Metabolism. 1997; 82(4):1293-1300.

[18] Bouret SG, Draper SJ, Simerly RB. Formation of projection pathways from the arcuate nucleus of the hypothalamus to hypothalamic regions implicated in the neural control of feeding behavior in mice. Journal of Neuroscience. 2004;24(11):27972805.

[19] Ahima RS, Osei SY. Leptin signaling. Physiology \& Behavior. 2004;81(2):223-241.

[20] Faggioni R, Feingold KR, Grunfeld C. Leptin regulation of the immune response and the immunodeficiency of malnutrition. FASEB Journal. 2001;15(14):2565-2571.

[21] Aleffi S, Petrai I, Bertolani C, et al. Upregulation of proinflammatory and proangiogenic cytokines by leptin in human hepatic stellate cells. Hepatology. 2005;42(6):1339-1348.

[22] Dötsch J, Nüsken K, Schroth M, Rascher W, Meißner U. Alterations of leptin and ghrelin serum concentrations in renal disease: simple epiphenomena? Pediatric Nephrology. 2005;20(6): 701-706.

[23] Beutler B, Cerami A. Cachectin (tumor necrosis factor): a macrophage hormone governing cellular metabolism and inflammatory response. Endocrine Reviews. 1988;9(1):57-66.

[24] Tracey KJ, Cerami A. Tumor necrosis factor: a pleiotropic cytokine and therapeutic target. Annual Review of Medicine. 1994;45:491-503.

[25] Wang S-S, Lee F-Y, Chan C-C, et al. Sequential changes in plasma cytokine and endotoxin levels in cirrhotic patients with bacterial infection. Clinical Science. 2000;98(4):419-425.
[26] Odeh M, Sabo E, Srugo I, et al. Serum levels of tumor necrosis factor-alpha correlate with severity of hepatic encephalopathy due to chronic liver failure. Liver International. 2004;24(2): $110-116$.

[27] Le J, Vilcek J. Interleukin 6: a multifunctional cytokine regulating immune reactions and the acute phase protein response. Laboratory Investigation. 1989;61(6):588-602.

[28] Deviere J, Content J, Denys C, et al. High interleukin-6 serum levels and increased production by leucocytes in alcoholic liver cirrhosis. Correlation with IgA serum levels and lymphokines production. Clinical and Experimental Immunology. 1989;77(2):221-225.

[29] Gerstner C, Schuetz T, Von Baehr V, et al. Correlation between energy expenditure, nutrient intake, malnutrition and activation of the inflammatory system in patients with hepatic cirrhosis. Journal of Hepatology. 2001;34(suppl 1):195-196.

[30] Onodera K, Kato A, Suzuki K. Serum leptin concentrations in liver cirrhosis: relationship to the severity of liver dysfunction and their characteristic diurnal profiles. Hepatology Research. 2001;21(3):205-212.

[31] Di Lelio A, Cestari C, Lomazzi A, Beretta L. Cirrhosis: diagnosis with sonographic study of the liver surface. Radiology. 1989;172(2):389-392.

[32] Bruix M, Sherman JM, Llovet JM, et al. Clinical management of hepatocellular carcinoma. Conclusions of the Barcelona2000 EASL conference. European Association for the Study of the Liver. Journal of Hepatology. 2001;35(3):421-430.

[33] Türkdoğan MK, Bozkurt H, Uygan I, et al. Chronic hepatitis delta virus infection in Van region of eastern Turkey. The Turkish Journal of Gastroenterology. 2005;16(1):17-20.

[34] Groshiede P, Van Damme P. Epidemiology of hepatitis B infection, prevention and control of hepatitis B in the comunity. In: Hallauer J, Jane J, McCloy E, Merheus A, Roure C, eds. Communicable Disease Series. No: 1. Geneva, Switzerland: World Health Organization, European Organization Office; 1996:1726.

[35] Uzunalimoglu Ö, Yurdaydin C, Cetinkaya H, et al. Risk factors for hepatocellular carcinoma in Turkey. Digestive Diseases and Sciences. 2001;46(5):1022-1028.

[36] Tajika M, Kato M, Mohri H, et al. Prognostic value of energy metabolism in patients with viral liver cirrhosis. Nutrition. 2002;18(3):229-234.

[37] Tacke F, Brabant G, Kruck E, et al. Ghrelin in chronic liver disease. Journal of Hepatology. 2003;38(4):447-454.

[38] Casanueva FF, Dieguez C. Ghrelin a new hormone implicated in the regulation of growth hormone secretion and body energy homeostasis. Growth, Genetics \& Hormones. 2004;20(1): $1-8$.

[39] Ockenga J, Bischoff SC, Tillmann HL, et al. Elevated bound leptin correlates with energy expenditure in cirrhotics. Gastroenterology. 2000;119(6):1656-1662.

[40] McCullough AJ, Bugianesi E, Marchesini G, Kalhan SC. Gender-dependent alterations in serum leptin in alcoholic cirrhosis. Gastroenterology. 1998;115(4):947-953.

[41] Bolukbas FF, Bolukbas C, Horoz M, et al. Child-Pugh classification dependent alterations in serum leptin levels among cirrhotic patients: a case controlled study. BMC Gastroenterology. 2004;4(1):23.

[42] Testa R, Franceschini R, Giannini E, et al. Serum leptin levels in patients with viral chronic hepatitis or liver cirrhosis. Journal of Hepatology. 2000;33(1):33-37. 
[43] Lin SY, Wang YY, Sheu WH. Increased serum leptin concentrations correlate with soluble tumour necrosis factor receptor levels in patients with cirrhosis. Clinical Endocrinology. 2002; 57(6):805-811.

[44] Greco AV, Mingrone G, Favuzzi A, et al. Serum leptin levels in post-hepatitis liver cirrhosis. Journal of Hepatology. 2000;33 (1):38-42.

[45] Comlekci A, Akpinar H, Yesil S, et al. Serum leptin levels in patients with liver cirrhosis and chronic viral hepatitis. Scandinavian Journal of Gastroenterology. 2003;38(7):779-786.

[46] Wahl DG, Dollet J-M, Kreher M, Champigneulle B, Bigard M-A, Gaucher P. Relationship of insulin resistance to proteinenergy malnutrition in patients with alcoholic liver cirrhosis: effect of short-term nutritional support. Alcoholism: Clinical and Experimental Research. 1992;16(5):971-978.

[47] Kwon SY, Kim SS, Kwon OS, et al. Prognostic significance of glycaemic control in patients with HBV and HCV-related cirrhosis and diabetes mellitus. Diabetic Medicine. 2005;22(11): 1530-1535.

[48] Williams EJ, Iredale JP. Liver cirrhosis. Postgraduate Medical Journal. 1998;74(870):193-202.

[49] Tilg H, Wilmar A, Vogel W, et al. Serum levels of cytokines in chronic liver diseases. Gastroenterology. 1992;103(1):264-274.

[50] Inui A. Cancer anorexia-cachexia syndrome: are neuropeptides the key? Cancer Research. 1999;59(18):4493-4501.

[51] Kotler DP. Cachexia. Annals of Internal Medicine. 2000;133(8): 622-634.

[52] Toda K, Kumagai N, Tsuchimoto K, et al. Induction of hepatic stellate cell proliferation by LPS-stimulated peripheral blood mononuclear cells from patients with liver cirrhosis. Journal of Gastroenterology. 2000;35(3):214-220. 


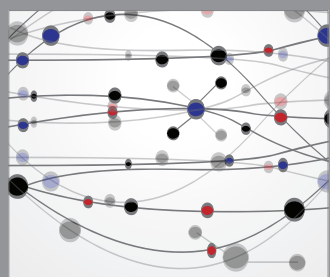

The Scientific World Journal
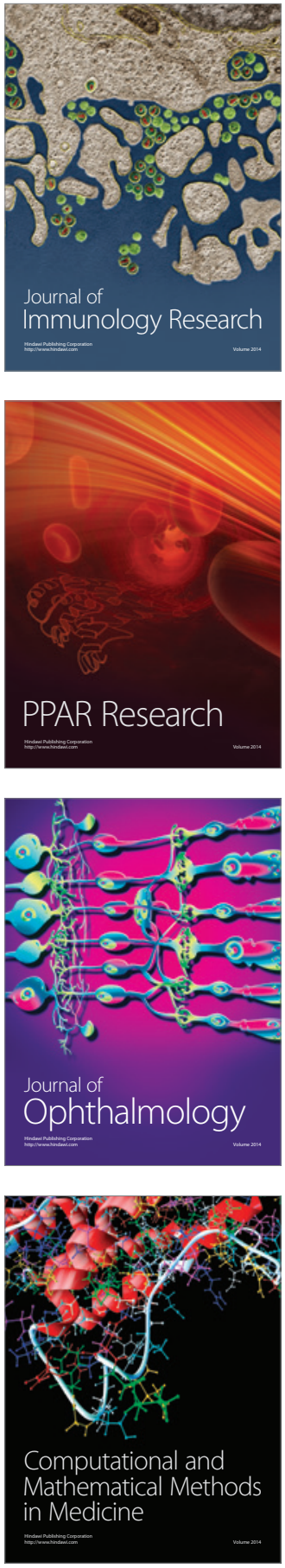

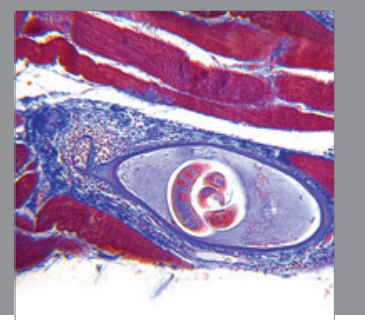

Gastroenterology

Research and Practice
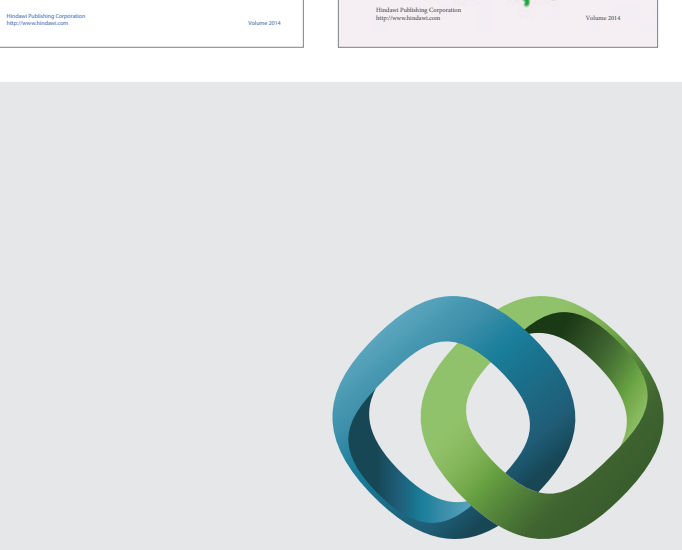

\section{Hindawi}

Submit your manuscripts at

http://www.hindawi.com
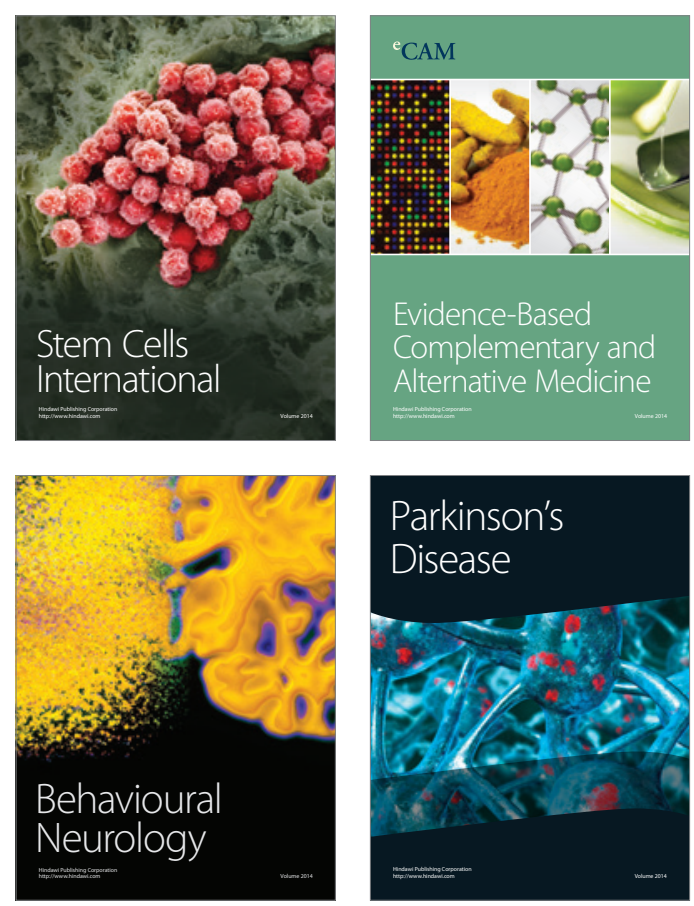

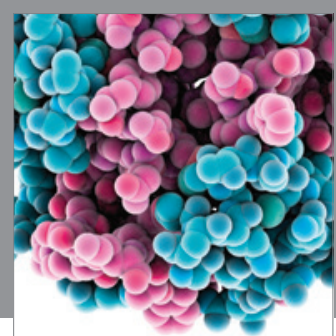

Journal of
Diabetes Research

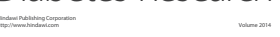

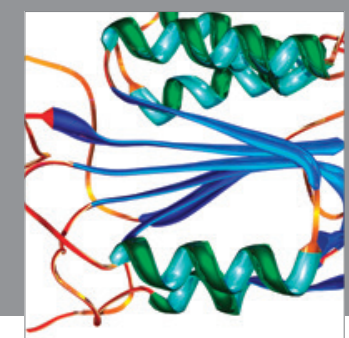

Disease Markers
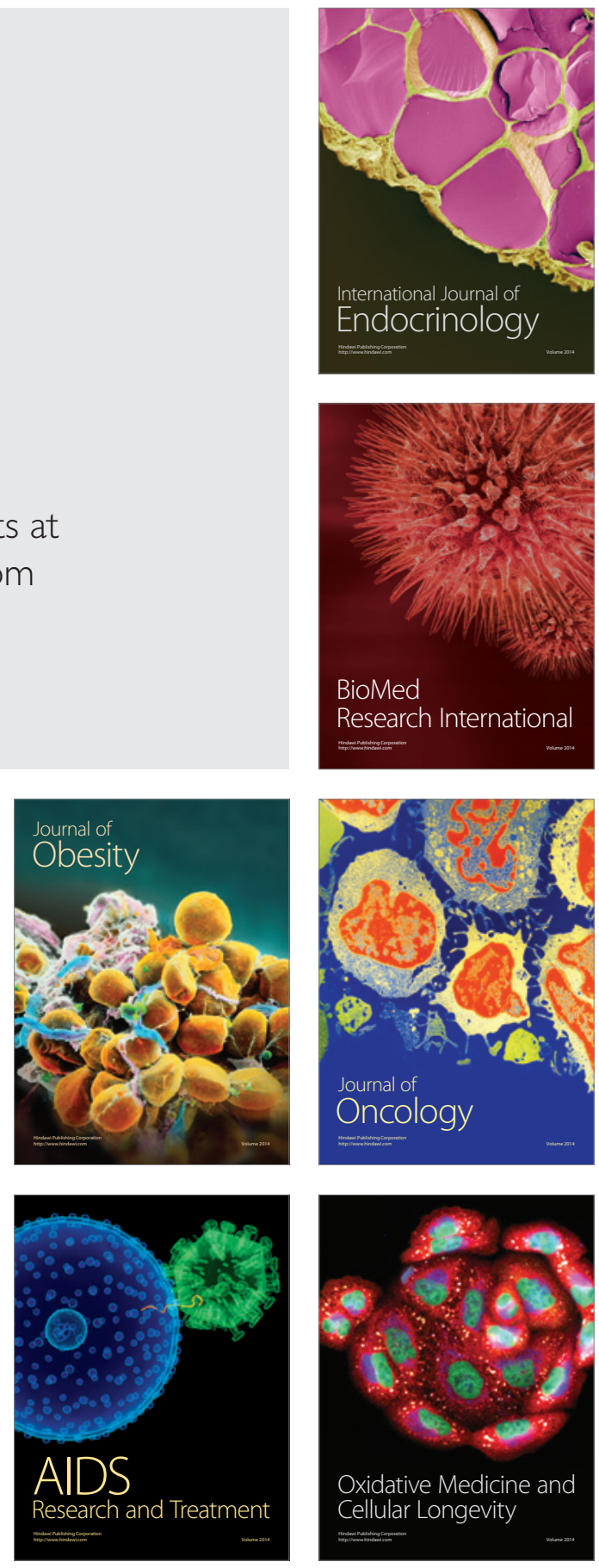